\title{
Host Responses to Transient Expression of Individual Genes Encoded by Tomato leaf curl virus
}

\author{
Luke A. Selth, ${ }^{1,2}$ John W. Randles, ${ }^{2}$ and M. Ali Rezaian' \\ ${ }^{1}$ Horticulture Unit, CSIRO Plant Industry, PO Box 350, Glen Osmond, South Australia and ${ }^{2}$ School of Agriculture and Wine, \\ The Univeristy of Adelaide, South Australia
}

Submitted 3 February 2003. Accepted 5 August 2003.

\begin{abstract}
The six open reading frames of Tomato leaf curl virus (TLCV) were expressed in host Nicotiana species using a Tobacco mosaic virus vector. Each of the genes, except that encoding the viral coat protein, produced a phenotypic effect when expressed in planta, but the corresponding untranslatable mutant genes were asymptomatic. The $C 1$ (Rep) gene invoked a hypersensitive response in Nicotiana clevelandii that restricted the viral construct to sites of infection. Expression of the $\boldsymbol{C} 2$ gene in $N$. benthamiana produced necrotic lesions on inoculated leaves as well as severe veinal necrosis on systemically infected leaves. This gene was also able to suppress post-transcriptional gene silencing in N. tabacum. C4 induced viruslike symptoms in host plants tested, providing further evidence for the involvement of this gene in symptom expression. Expression of the $V 1$ and $C 3$ genes caused severe stunting of $N$. benthamiana plants, indicating they may also have a role in symptom development. These results reveal that a complex set of interactions between the TLCV gene products and host factors occurs in planta, and these are discussed in relation to our current understanding of TLCV gene function.
\end{abstract}

Additional keywords: Begomovirus, Geminiviridae, gene expression, phenotypic effects, suppressor of post-transcriptional gene silencing.

Tomato leaf curl virus (TLCV) is a member of the Geminiviridae, a large and diverse family of plant viruses that have emerged globally as important agricultural pathogens. Geminiviruses are characterized by twinned isometric particles containing single-stranded DNA molecules of 2.5 to $3.0 \mathrm{~kb}$ and have been divided into four genera based on their genomic organization and insect vector (van Regenmortel et al. 2000). Begomoviruses, belonging to the largest genus, are transmitted by the whitefly Bemisia tabaci and commonly have bipartite genomes. TLCV is one of the few members of this genus that contains a single-component genome (Dry et al. 1993), which encodes all of the functions necessary for a complete infection cycle.

Geminiviral genomes contain divergent coding sequences separated by $5^{\prime}$ intergenic regions. The genome of TLCV has two open reading frames (ORF) on the virion-sense strand and four on the complementary-sense strand (Fig. 1A). In recent years, geminiviral gene function has been studied intensively (Hanley-Bowdoin et al. 1999). The role of the viral replication protein (Rep) encoded by the $C l$ gene has come under particu-

Corresponding author: M. A. Rezaian; Telephone: + (618) 8303 8634; Fax: + (618) 8303 8601; E-mail: ali.rezaian@csiro.au lar scrutiny. Rep is a multifunctional protein that is able to i) nick and religate viral DNA to initiate plus-strand DNA replication (Heyraud-Nitschke et al. 1995; Laufs et al. 1995), ii) bind the viral origin of replication in a virus-specific manner (Behjatnia et al. 1998; Gladfelter et al. 1997), iii) regulate its own expression at the transcriptional level (Sunter et al. 1993), iv) hydrolyze ATP (Desbiez et al. 1995), and v) induce host replication machinery, presumably to enable virus DNA replication in differentiated plant cells (Nagar et al. 1995). The $C 2$ gene product is able to transactivate expression of the virionsense genes at the level of transcription in a virus nonspecific manner (Sunter and Bisaro 1992; Sunter et al. 1994; Dry et al. 2000). $C 3$ encodes a replication accessory factor that enhances viral DNA accumulation through an unknown mechanism (Sunter et al. 1990). The Vl gene has been implicated in cellto-cell viral spread in Maize streak virus (Lazarowitz et al. 1989) and in ssDNA accumulation in TLCV (Rigden et al. 1993). The protein encoded by the $C 4$ gene seems to be functional only in some monopartite geminiviruses and has been associated with symptom expression (Krake et al. 1998; Latham et al. 1997) and virus movement (Jupin et al. 1994).

To further describe the role of individual TLCV proteins in the infection cycle, we have transiently expressed each of the genes in various host plants using a Tobacco mosaic virus (TMV)-based vector. This episomal expression system allowed us to bypass problems associated with transgenic expression of the TLCV ORF, such as positive selection against integration of the $C l$ gene into transformed cells (Dry et al. 2000). The results indicate that all of the TLCV gene products except the coat protein interact with the host to induce a noticeable phenotypic effect.

\section{RESULTS}

Expression of TLCV genes in planta.

Following a preliminary comparison of a number of TMVbased vectors, we chose to use 30B (Fig. 1B) (Shivprasad et al. 1999) in this study, based on its mild pathogenicity and its ability to express a green fluorescent protein reporter gene to high levels in host plants tested. Infectious viral RNA transcripts synthesized from the 30B-TLCV gene constructs (hereafter referred to as, for example, 30B-C1 and 30B-C1mut) were mechanically inoculated onto Nicotiana benthamiana, N. clevelandii, or $N$. tabacum (tobacco) plants. The natural host of TLCV, Lycopersicon esculentum (tomato), could not be used in this study, as it was resistant to infection by $30 \mathrm{~B}$.

Analysis of systemically infected leaves by Northern blotting 10 days postinoculation (dpi) identified two main RNA species for each construct (Fig. 2A), genomic 30B RNA and a subgenomic RNA of a size corresponding to the gene insert, 
suggesting that the TLCV sequences inserted into $30 \mathrm{~B}$ were stably maintained during infection. The exception was tissue obtained from plants inoculated with 30B-C1, which did not contain detectable levels of TMV-derived RNA (Fig. 2A, lane 3).

$N$. benthamiana, $N$. clevelandii, and tobacco plants infected with the parental 30B vector or constructs expressing mutated forms of the ORF developed mild curling and mosaic symptoms on inoculated and systemically infected leaves 5 to 8 dpi. In contrast, plants infected with each of the $30 \mathrm{~B}$ constructs containing wild-type TLCV gene sequences, except for 30BV2 encoding the coat protein, exhibited distinct phenotypic effects. These symptoms were reproducible in independent experiments, summarized in Table 1. The lack of response in plants inoculated with $30 \mathrm{~B}-\mathrm{V} 2$ was consistent with our previous observation that transgenic tobacco plants expressing the coat protein develop normally (I. Dry and M. Rezaian, personal communication) and with work by Frischmuth and Stanley (1998) in which the coat protein from African cassava mosaic virus (ACMV) was expressed in N. benthamiana without inducing a phenotypic effect.
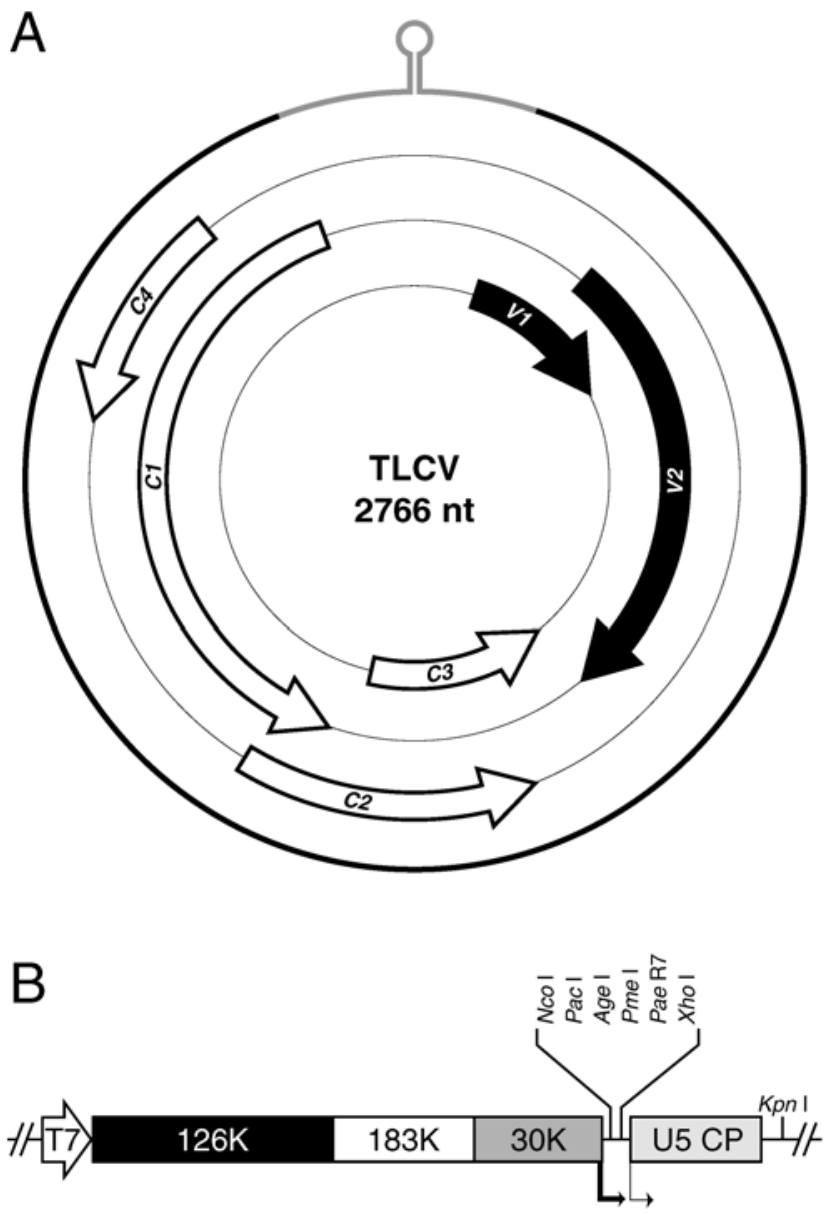

Fig. 1. A, Genome organization of Tomato leaf curl virus (TLCV). The stem loop is located within the intergenic region, delineated in gray. Locations of the two virion-sense (V1 and V2) and four complementarysense $(\mathrm{C} 1, \mathrm{C} 2, \mathrm{C} 3, \mathrm{C} 4)$ viral open reading frames are shown by arrows. B, Schematic representation of the Tobacco mosaic virus (TMV)-30B genome. The diagram shows the location of the viral genes in the vector that encode the replication-associated proteins (126K and $183 \mathrm{~K})$, the movement protein $(30 \mathrm{~K})$, and the coat protein (CP) from the U5 variant of Tobacco mild green mosaic virus (TMGMV) (U5 CP). The locations of the TMV CP subgenomic promoter (thick arrow) and a second subgenomic promoter from TMGMV (thin arrow) are shown, as is the position of the $\mathrm{T} 7$ promoter and restriction sites in the polylinker.
Expression of Rep induces a hypersensitive response in $N$. clevelandii.

Infection of $N$. clevelandii with $30 \mathrm{~B}-\mathrm{C} 1$ resulted in the development of necrotic local lesions on inoculated leaves, resembling a hypersensitive response (HR), at approximately 8 dpi (Fig. 3A). This severe host response appeared to restrict the viral construct to infected regions, since noninoculated leaves appeared to be healthy, not even displaying the background symptoms caused by $30 \mathrm{~B}$ infection, and TMV RNA was below detectable levels in this tissue (Fig. 2A, lane 3). In contrast, 30B-C1mut was shown to systemically infect plants (data not shown) but did not cause local lesions (Fig. 3B).

The functional domains of the geminiviral Rep have been well characterized (Hanley-Bowdoin et al. 1999). The N-terminal 184 amino acids of Rep contain the DNA binding and cleavage/ligation activities and also the domains responsible for oligomerization and interactions with $\mathrm{C} 3$ and host factors, while the $\mathrm{C}$-terminus of the protein is responsible for its ATPase activity. Based on these data, two truncations of the $C 1$ gene, one encoding the first 184 amino acids and the other encoding amino acids 184 to 362, were examined in $N$. clevelandii. $30 \mathrm{~B}-\mathrm{Cl}_{1-184}$ was able to induce local lesion formation (Fig. 3C), but plants infected with $30 \mathrm{~B}-\mathrm{Cl}_{184-362}$ were normal except for background symptoms associated with 30B infection (Fig. 3D). To further delineate the domain responsible for the local lesion response, two more 30B vectors expressing amino acids 1 to 100 and 100 to 184 of Rep were tested in $N$. clevelandii, but neither induced local lesions (data not shown). The production of subgenomic RNAs containing truncated $C 1$ sequences (Fig. 2B) confirmed that the lack of symptoms in these plants was not due to defective constructs.

Interestingly, $N$. benthamiana appeared to be immune to the Rep-induced HR-like response. While plants inoculated with 30B-C1mut developed curling and mottling symptoms indistinguishable from those produced by the $30 \mathrm{~B}$ vector alone, the TMV construct expressing wild-type Rep was unable to establish a symptomatic infection in this host. However, 14 dpi with $30 \mathrm{~B}-\mathrm{C} 1$, leaf tissue extracts from inoculated leaves of nonsymptomatic $N$. benthamiana were passaged onto healthy $N$. clevelandii and produced the local lesions, indicating that $N$. benthamiana is a carrier of this viral construct but is able to suppress symptom development.

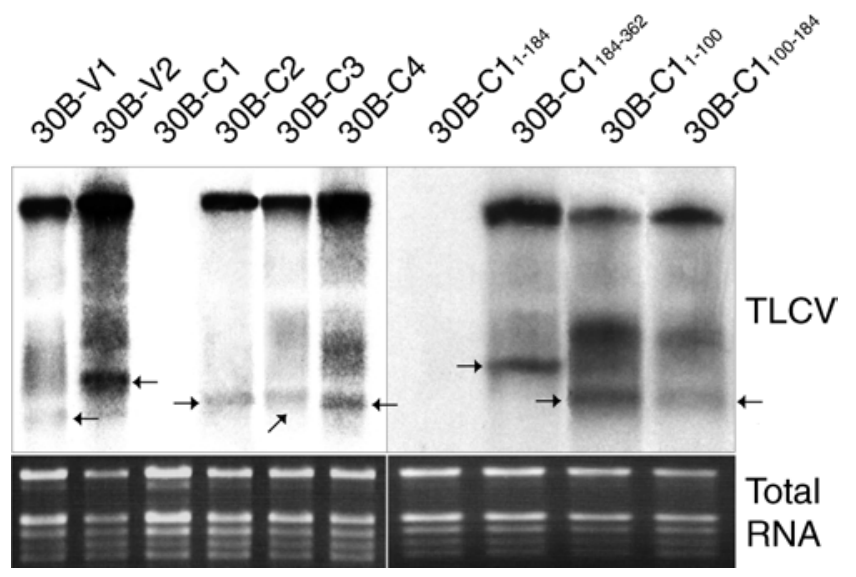

Fig. 2. Northern blot analysis of RNA from Nicotiana clevelandii plants inoculated with $30 \mathrm{~B}$ constructs containing the Tomato leaf curl virus (TLCV) genes. Subgenomic RNAs containing TLCV gene sequences are indicated with arrows. To verify uniform loading of the RNA, $500 \mathrm{ng}$ of each sample was electrophoresed in a $1.2 \%$ agarose gel and was stained with ethidium bromide (lower panel). 
The $\mathrm{C} 2$ protein is a pathogenicity determinant and a suppressor of post-transcriptional gene silencing.

Expression of the $C 2$ gene produced necrotic lesions and some veinal necrosis on inoculated leaves of $N$. benthamiana (Fig. 3E). These symptoms spread systemically, with new leaves exhibiting severe veinal necrosis extending into vascular regions (Fig. 3G). Similar symptoms have been observed when AC2 from ACMV was transiently expressed in $N$. benthamiana using a Potato virus $X(\mathrm{PVX})$-based vector (Hong et al. 1997). The pathogenicity of AC2 was shown to be linked to its function as a suppressor of post-transcriptional gene silencing (PTGS) in N. benthamiana (Voinnet et al. 1999), a finding which was later reproduced for the analogous protein $(\mathrm{C} 2)$ from the monopartite begomovirus Tomato yellow leaf curl virus (TYLCV)-China (van Wezel et al. 2002b). To test whether TLCV C2 could disrupt PTGS, a $C 2$ expression vector (pART27-C2; discussed below) was introduced into transgenic tobacco plants containing a silenced $\beta$-glucuronidase (GUS) transgene (Wesley et al. 2001) by Agrobacterium tumefaciens infiltration. Plants treated with the empty pART27 vector did not exhibit GUS expression (Fig. 4B), whereas agroinfiltration of plants with pART27-C2 resulted in activation of GUS expression after 5 days (Fig. 4A). These results indicate that the TLCV C2 protein is a suppressor of PTGS in tobacco.

\section{Expression of the V1, C3, and C4 genes}

produces viruslike symptoms in $N$. benthamiana.

The V1, C3, and $C 4$ genes all produced a noticeable phenotypic effect when expressed in the TLCV hosts $N$. benthamiana and $N$. clevelandii. Both 30B-V1 and 30B-C3 caused significant stunting of $N$. benthamiana plants 14 dpi compared with mutant controls (Fig. 3I and J). 30B-C4 produced severe viruslike symptoms on leaves of infected tobacco plants, including rugosity, blistering, and curling of leaf margins (Fig. 3K) compared with the mild mosaic observed after inoculation with 30B-C4mut (Fig. 3L). The phenotype induced by expression of $C 4$ using the episomally replicating $30 \mathrm{~B}$ was similar to that observed in tobacco plants stably transformed with this gene (Krake et al. 1998). N. benthamiana plants infected with 30B$\mathrm{C} 4$ exhibited more severe symptoms than those observed in tobacco, including zigzag growth and major deformation of new leaves (data not shown).

\section{DISCUSSION}

The work described here represents the first study of the phenotypes induced by each of the major genes of a single geminivirus, when expressed in plants in the absence of other viral proteins, and has provided new insight into TLCV-host interactions. Apart from the lack of response induced by 30BV2, we observed phenotypes ranging from stunting (caused by expression of $C 3$ and $V 1)$ to viruslike symptoms $(C 4)$ and severe necrosis $(C 1$ and $C 2)$. In comparison, a normal TLCV in- fection in which all of the viral proteins are available causes symptoms in $N$. benthamiana and $N$. clevelandii that include stunting, systemic vein clearing, and curling and mottling of new leaves (M. Rezaian, personal communication).

The most striking effect was caused by expression of the $C 1$ gene, which resulted in the development of necrotic local lesions on inoculated leaves. During the preparation of this manuscript, van Wezel and associates (2002a) published work describing the ability of Rep from TYLCV-China and ACMV to induce a HR-like response in $N$. benthamiana when expressed from a PVX-based vector. We have noted distinct differences between host reactions to TLCV Rep and these homologous begomoviral proteins. First, induction of local lesions in $N$. clevelandii by TLCV Rep confined the viral construct to infection sites, whereas the PVX vectors used to express TYLCVChina and ACMV Rep were able to escape the Rep-triggered HR-like response sites and establish a systemic infection in $N$. benthamiana. In one of our experiments, systemic symptoms similar to those caused by the $C 1$ mutant were observed on a plant infected with 30B-C1. However, subsequent sequencing of the progeny virus cDNA revealed that it was an escape mutant, containing a deletion in the $C l$ gene from nucleotides 123 to 892 . The disparity between $30 \mathrm{~B}-\mathrm{C} 1$ and the PVX constructs in their ability to systemically infect plants may reflect one or both of the different viral vectors or host plants used. Alternatively, it is possible that TLCV Rep initiates a more severe host response than its homologues when overexpressed in plants. Consistent with this theory, we have failed to generate transgenic tobacco plants expressing TLCV Rep (L. Krake, I. Dry, and M. Rezaian, personal communication), but the Reps from ACMV (Hong and Stanley, 1996) and Tomato golden mosaic virus (TGMV) (Hanley-Bowdoin et al. 1990) as well as two truncated $C 1$ genes from TYLCV-Sardinia (Brunetti et al. 1997; Noris et al. 1996) have been expressed in transgenic plants using the cauliflower mosaic virus $35 \mathrm{~S}$ promoter without inducing any phenotypic effects.

Another apparent difference between our results and those obtained by van Wezel and associates (2002a) was the inability of 30B-C1 to establish a symptomatic infection on $N$. benthamiana. This was a surprising observation, since the symptoms induced by the other $30 \mathrm{~B}$ constructs were generally more pronounced in this host as compared with $N$. clevelandii. Given that inoculation of $N$. clevelandii plants with tissue from apparently healthy $N$. benthamiana invoked the HR-like response, it appeared as if the viral construct could replicate in N. benthamiana but at very low levels such that it was unable to produce TMV symptoms or synthesize Rep at a concentration that activates the HR-like response. Alternatively, 30B-C1 may have been restricted to the initially infected cells by the initiation of a more rapid HR-like response. This effective host response that resulted in suppression of the $30 \mathrm{~B}$ vector was clearly initiated by expression of $C 1$, since it was not observed with any of the other viral constructs, including 30B-C1mut.

Table 1. Infectivity and symptoms induced by 30B-Tomato leaf curl virus gene constructs

\begin{tabular}{|c|c|c|c|c|c|c|}
\hline \multirow[b]{2}{*}{ Viral construct } & \multicolumn{3}{|c|}{ Nicotiana benthamiana } & \multicolumn{3}{|c|}{ N. clevelandii } \\
\hline & $\operatorname{Exp} 1^{a}$ & $\operatorname{Exp} 2$ & Symptoms $^{b}$ & $\operatorname{Exp} 1$ & $\operatorname{Exp} 2$ & Symptoms ${ }^{a}$ \\
\hline 30B-C1 & $0 / 3$ & $\ldots$ & AS & $3 / 3$ & $6 / 6$ & NLL \\
\hline $30 \mathrm{~B}-\mathrm{C} 2$ & $3 / 3$ & $5 / 6$ & VN & $3 / 3$ & $6 / 6$ & VN \\
\hline 30B-C3 & $3 / 3$ & $6 / 6$ & ST, LC & $3 / 3$ & $6 / 6$ & ST \\
\hline $30 \mathrm{~B}-\mathrm{C} 4$ & $3 / 3$ & $6 / 6$ & TW, LC, BL & $3 / 3$ & $6 / 6$ & TW, LC, BL \\
\hline 30B-V1 & $3 / 3$ & $6 / 6$ & ST & $3 / 3$ & $6 / 6$ & ND \\
\hline 30B-V2 & $3 / 3$ & $6 / 6$ & ND & $3 / 3$ & $6 / 6$ & ND \\
\hline
\end{tabular}

${ }^{a}$ Results of all experiments are given as number of plants symptomatic/number of plants inoculated.

b Symptom abbreviations: AS = asymptomatic, NLL = necrotic local lesions, VN = veinal necrosis, $\mathrm{ST}=$ stunting, $\mathrm{LC}=$ leaf curling, TW $=$ stem twisting, $\mathrm{BL}=$ blistering, and $\mathrm{ND}=$ no major differences to control. 

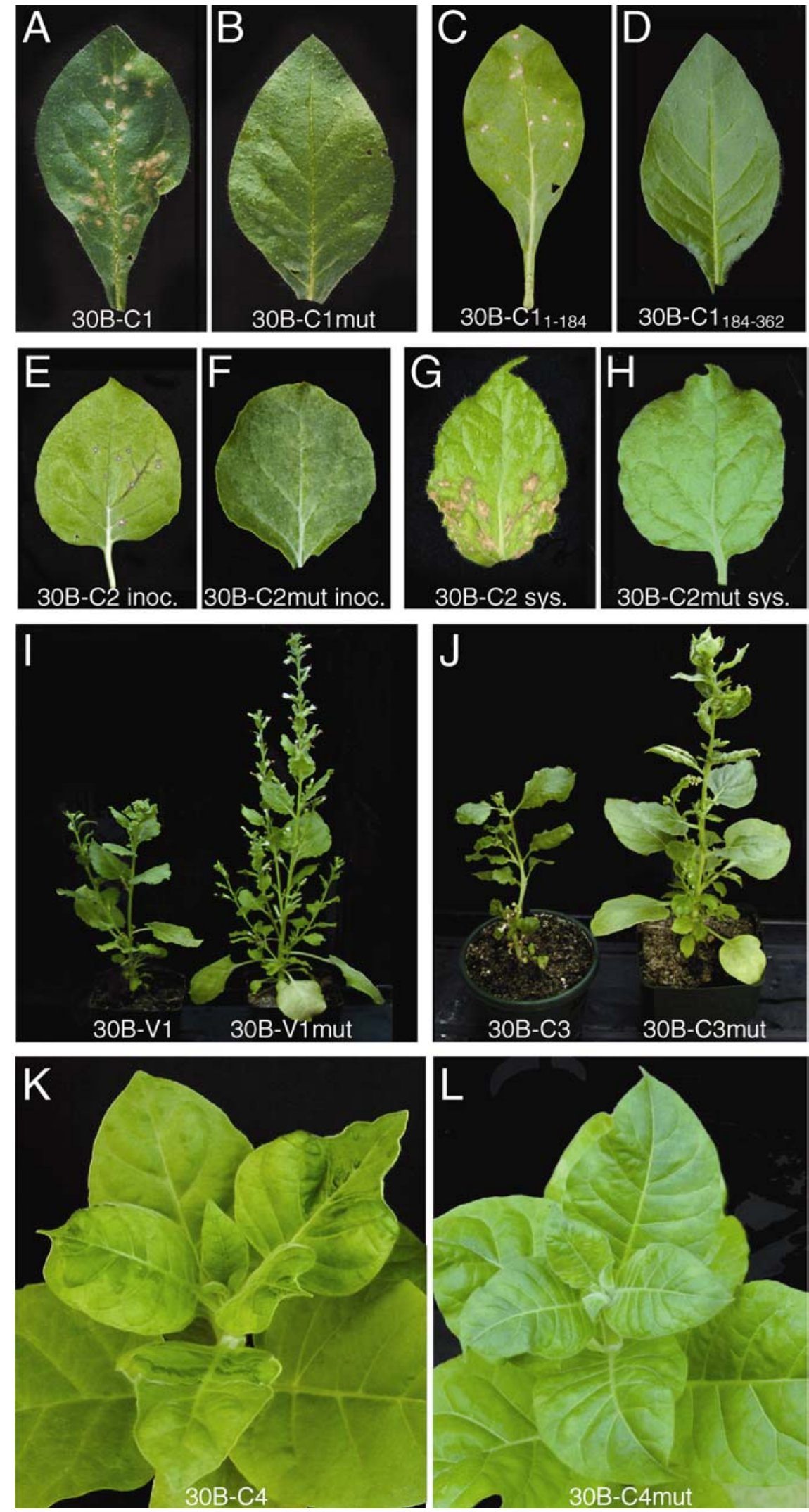

Fig. 3. Symptoms of plants infected with 30B constructs expressing Tomato leaf curl virus (TLCV) genes and mutant controls 14 days postinoculation. A to $\mathbf{D}$, Inoculated leaves from Nicotiana clevelandii plants. $\mathbf{E}$ to $\mathbf{J}$, Infected $N$. benthamiana leaves or whole plants. $\mathbf{K}$ to $\mathbf{L}$, Tobacco plants. $\mathbf{A}$, Local lesions induced by 30B-C1; B, 30B-C1mut; C, 30B-C1 $1_{1-184} ; \mathbf{D}, 30 \mathrm{~B}-\mathrm{Cl}_{184-362} ; \mathbf{E}$ and $\mathbf{G}$, inoculated and systemic leaves from a plant infected with 30B$\mathrm{C} 2 ; \mathbf{F}$ and $\mathbf{H}$, inoculated and systemic leaves from a plant infected with 30B-C2mut; I and J, stunting induced by 30B-V1 and 30B-C3, respectively, (plants on left) compared with mutant controls (right); K, viruslike symptoms induced by 30B-C4; and L, 30B-C4mut. 
The HR-like response induced by ACMV Rep is mediated by a domain between amino acids 119 to 179 (van Wezel et al. 2002a). In addition, this protein possesses two regions that modulate the HR-like phenotype; amino acids 86 to 118 represent a repressor sequence while amino acids 1 to 85 counter this repression and restore the wild-type activity. In our study, $30 \mathrm{~B}-\mathrm{C} 1_{1-184}$ was able to invoke a HR-like response but $30 \mathrm{~B}-\mathrm{C} 1_{100-184}$ did not produce local lesions, despite expressing comparable levels of subgenomic RNA encoding the Rep truncation (Fig. 2B). Assuming the findings of van Wezel and associates (2002a) are applicable to TLCV Rep, we propose that amino acids 100 to 184 may contain just the repressor domain, whereas the expanded N-terminal construct ( 1 to 184 ) possesses both positive and negative modulating sequences.

A number of geminiviral Reps are able to interact with the tumor suppressor protein retinoblastoma (Rb) (Ach et al. 1997; Liu et al. 1999; Xie et al. 1995). It is tempting to speculate that the toxicity of TLCV Rep represents deregulation of the cell cycle following interaction with $\mathrm{Rb}$. This theory is consistent with the observation that the N-terminal 184 amino acids of TLCV Rep, within which the Rb binding site is predicted (Kong et al. 2000), are sufficient to induce the HR. However, transgenic plants stably expressing TGMV Rep are asymptomatic. This discrepancy may reflect a difference between the proposed interaction between TLCV Rep and Rb compared with that identified for TGMV Rep. Alternatively, TLCV Rep may impact on other host processes involving factors other than $\mathrm{Rb}$. This argument is substantiated by the recent identification of three new cellular partners of TGMV Rep, a Ser/Thr kinase, a kinesin, and histone H3 (Kong and Hanley-Bowdoin 2002). We have attempted to identify host factors involved in the HR-like response invoked by TLCV Rep, using yeast systems, and have found that the protein also invokes an extreme toxic effect in yeast cells (unpublished data).

Another gene product from TLCV, the C2 protein, was also shown to elicit a severe host reaction when expressed by $30 \mathrm{~B}$ in Nicotiana hosts. Further characterization of $\mathrm{C} 2$ revealed that it could suppress PTGS, an RNA-mediated defense mechanism in plants that is thought to have evolved to target foreign nucleic acid-based pathogens. It is interesting to note that virusinduced resistance strategies that have proven successful for many RNA and DNA viruses, such as expression of sense and antisense viral sequences in transgenic plants (Baulcombe 1999), have been ineffective against TLCV. In fact, transgenic plants expressing TLCV sequences, including the $V 2$ and $C 4$ genes and antisense constructs of all six TLCV genes, were still susceptible to TLCV infection (unpublished data). Furthermore, in this study we tested the replication of TLCV in plants infected with the 30B-TLCV gene constructs and found no evidence of resistance to TLCV (data not shown). A possible explanation for these results is that TLCV is able to evade or suppress silencing mechanisms via the function of $\mathrm{C} 2$.

Both $A C 2$ from ACMV and $C 2$ from TYLCV-China have been transiently expressed in $N$. benthamiana, using a PVX vector (Voinnet et al. 1999; van Wezel et al. 2001). While AC2 invoked a phenotype reminiscent of that produced by TLCV $\mathrm{C} 2$, the $\mathrm{C} 2$ protein from TYLCV-China induced markedly different symptoms, including necrotic ringspots on inoculated leaves and necrotic vein banding on systemically infected leaves. This phenotypic variation may reflect differences in the experimental systems used or illustrate functional diversity between geminiviral $\mathrm{C} 2$ proteins.

30B-V1 caused severe stunting of both $N$. benthamiana and $N$. clevelandii plants compared with the mutant control (Fig. 3I). Previous work in this laboratory (Rigden et al. 1993) showed that a TLCV derivative containing a frame-shift muta- tion in the $V 1$ gene was capable of systemically infecting tomato and these plants contained titers of viral DNAs reduced about fivefold compared with wild-type infections (as determined by visual assessment of Southern blots). However, these plants were asymptomatic despite the significant levels of TLCV accumulation. Our finding that 30B-V1 induces a host response substantiates this earlier data implicating $V 1$ in symptom expression.

Similarly to the $V 1$ gene, expression of $C 3$ induced noticeable stunting of $N$. benthamiana and $N$. clevelandii. TMGV AL3 mutants replicate far less efficiently than their wild-type counterparts and, hence, show delayed and attenuated symptoms in infected plants (Sunter et al. 1990). However, to date there has been no experimental evidence to suggest that geminivirus $C 3$ gene products play a direct role in symptom development, as was observed in this study. The recent finding that AL3 interacts with $\mathrm{Rb}$ (Settlage et al. 2001) provides a possible explanation for our observations. It is conceivable that $\mathrm{C} 3$ may disrupt the plant $\mathrm{Rb}$ control pathway when expressed in an uncontrolled manner. Alternatively, this result may be due to one or more interactions between $\mathrm{C} 3$ and either the TMV vector, other host factors, or both.

30B-C4 induced severe viruslike symptoms, including rugosity and deformation of new leaves, resembling those observed in tobacco plants transformed with $C 4$ (Krake et al. 1998). This provides further evidence for a possible role of the TLCV C4 gene product in the regulation of host cell division, as has been described for the homologue from Beet curly top virus, a monopartite curtovirus (Latham et al. 1997). In contrast, the $\mathrm{C} 4$ protein from a geminivirus more closely related to TLCV, TYLCV-China, does not appear to interfere with cell cycle control, since a PVX C4 expression vector did not produce a phenotype in $N$. benthamiana (van Wezel et al. 2002a). The reasons for such diversity between the phenotypic effects induced by the $C 4$ genes from TLCV and TYLCV-China are unknown. Consistent with this finding, functional differences between the $\mathrm{C} 4$ proteins of these viruses have been reported before; a TYLCV-Sardinia derivative containing an untranslatable $C 4$ gene was unable to move systemically throughout tomato plants (Jupin et al. 1994), whereas an equivalent TLCV C4 mutant spread normally in this host (Rigden et al. 1994). van Wezel and associates (2002a) did observe that expression of the ACMV and TYLCV-China $C 4$ genes, despite their apparent lack of ability to invoke a phenotype, caused an augmentation of the Rep-mediated HR-like response when coexpressed with this protein, suggesting that they modulate the interaction between Rep and plant factors. It remains to be seen whether TLCV C4, or indeed any of the other TLCV proteins, possesses this activity.

It is important to note that the host responses observed in this study are caused by high-level and unregulated expression
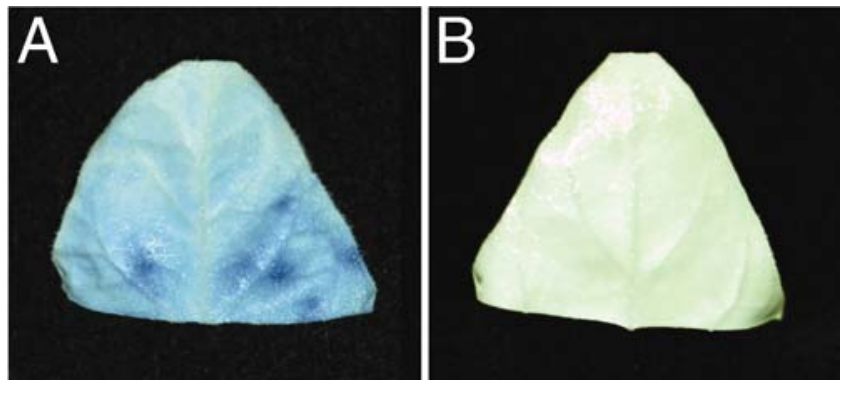

Fig. 4. Suppression of post-transcriptional gene silencing (PTGS) by C2. Transgenic tobacco plants exhibiting PTGS of a $\beta$-glucuronidase gene were agroinfiltrated with cells containing $\mathbf{A}$, a $C 2$ expression vector or $\mathbf{B}$, an empty vector. 
of the TLCV genes in association with a TMV-based vector. In a normal TLCV infection, however, transcription of viral genes is a tightly controlled process. For example, Rep represses its own expression at the level of transcription (Sunter et al. 1993). The toxicity exhibited by TLCV Rep when produced in an uncontrolled manner by $30 \mathrm{~B}$ in $N$. clevelandii highlights the importance of this regulation. Furthermore, gene expression by 30B may not be limited to cells normally invaded by TLCV, possibly resulting in further exaggeration of the phenotypic effects. It is also plausible that the host responses to TLCV gene expression could be altered by one or more interactions between TLCV genes and the TMV vector. In this study, we were unable to analyze production of TLCV-encoded proteins in infected plants, because antibodies to the TLCV proteins were not available. However, the different responses induced by the TLCV gene constructs and their absence when mutant counterparts were used provides compelling evidence that translation of the genes was occurring.

Our results indicate that each of the TLCV genes, except that encoding the coat protein, may interfere with host processes during viral infection. Thus, geminivirus pathogenesis may involve a more complex pattern of host interaction than previously realized. We are currently attempting to identify the host factors involved in these interactions using the yeast twohybrid system.

\section{MATERIALS AND METHODS}

\section{Construction of 30B-based vectors.}

The TLCV genes (Fig. 1A) and their mutant counterparts were cloned into 30B (Fig. 1B) to generate a set of episomally replicating expression vectors. Wild-type gene sequences were amplified by polymerase chain reaction (PCR) using platinum Taq high fidelity DNA polymerase (Invitrogen, Carlsbad, CA, U.S.A.). A TLCV monomer DNA obtained from pTLC4 (Dry et al. 1993) was used as the template in all reactions, except those amplifying $C 1$ sequences. In these reactions, a TLCV mutant containing $\mathrm{T}$ to $\mathrm{C}$ substitutions at positions 2,457 and 2,463 (Rigden et al. 1994), which disrupt two potential initiation codons for $C 4$, was employed. Products were A-tailed with Taq DNA polymerase and were ligated into pGEM-T Easy (Promega, Madison, WI, U.S.A.). After confirming the integrity of the genes by sequencing, they were excised by digestion with EcoRI or NotI, were end-filled with T4 DNA polymerase, and were ligated into the $P m e I$ restriction enzyme site of 30B. The mutant genes were amplified using modified forward primers that lack the initiation codon and introduce a frame-shift mutation (insertion of a $\mathrm{G}$ immediately before the second codon of the gene) and were subsequently cloned into $30 \mathrm{~B}$ as described for the wild-type versions. This cloning strategy was also used to ligate truncations of $C 1$ (nucleotides 1 to $552\left[\mathrm{C}_{1-184}\right], 549$ to $1089\left[\mathrm{C}_{184-362}\right], 1$ to $300\left[\mathrm{C}_{1-100}\right]$, and 297 to $\left.552\left[\mathrm{C1}_{100-184}\right]\right)$ generated by PCR into 30B.

\section{In vitro transcription and inoculation of plants.}

30B constructs were linearized by digestion with KpnI or PstI, and capped viral RNA was synthesized using an mMessage mMachine large scale in vitro $\mathrm{T} 7$ transcription kit (Ambion, Austin, TX, U.S.A.). N. benthamiana or N. clevelandii plants were mechanically inoculated by abrading approximately 500 ng of transcript in $5 \mu \mathrm{l}$ of sterile water onto single leaves, after dusting the leaf surface with Carborundum.

\section{RNA extraction and analysis.}

Total RNA from infected plants was extracted by grinding $250 \mathrm{mg}$ of frozen leaf tissue with $750 \mu \mathrm{l}$ phenol/chloroform/isoamyl alcohol (P/Cl/IAA) and $750 \mu \mathrm{l}$ RNA extraction buffer (50 mM Tris $\mathrm{HCl}$ [pH 8.0], $100 \mathrm{mM} \mathrm{NaCl}, 5$ mM EDTA [ethylenediaminetetra-acetic acid], 2\% sodium dodecyl sulphate [SDS]). The RNA was extracted twice more with $750 \mu \mathrm{P} / \mathrm{Cl} / \mathrm{IAA}$, was ethanol-precipitated at $-20^{\circ} \mathrm{C}$, and was resuspended in sterile water. Sample RNA $(5 \mu \mathrm{g})$ was denatured with denaturing buffer (Lewandowski and Dawson 1998) for $10 \mathrm{~min}$ at $65^{\circ} \mathrm{C}$, was cooled on ice, mixed with loading buffer, and analyzed on $1.2 \%$ agarose MOPS gels containing $2 \mathrm{M}$ formaldehyde. Transfer of RNA from the gel to ZetaProbe membrane (Bio-Rad, Hercules, CA, U.S.A.) was performed overnight in $10 \times \mathrm{SSC}(1 \times \mathrm{SSC}$ is $0.15 \mathrm{M} \mathrm{NaCl}$ plus $0.015 \mathrm{M}$ sodium citrate) using a TurboBlotter (Schleicher \& Schuell, Dassel, Germany). RNA on membranes was hybridized with ${ }^{32} \mathrm{P}$-labeled probe specific to TLCV synthesized using a Rediprime II DNA labeling system (Amersham Biosciences, Little Chalfont, England). Membranes were washed once at $65^{\circ} \mathrm{C}$ in $2 \times \mathrm{SSC}, 0.1 \% \mathrm{SDS}$ and twice at $65^{\circ} \mathrm{C}$ in $0.1 \times \mathrm{SSC}$, $0.1 \%$ SDS. Radioactively labeled bands were detected by autoradiography.

\section{Agroinfiltrations and analysis of GUS activity.}

The binary vector pART27 (Gleave 1992) was used to express the $C 2$ gene in transgenic tobacco plants to test for suppression of PTGS. The entire gene was first cloned as a blunt fragment into the SmaI site of the shuttle vector pART7. A NotI fragment containing the $35 \mathrm{~S}$ promoter, the $C 2 \mathrm{ORF}$, and the Nos terminator sequence was then transferred into NotIdigested pART27 to generate pART27-C2.

After electroporation of A. tumefaciens C58 with pART27$\mathrm{C} 2$, cells were grown for two nights on Luria broth agar containing the appropriate antibiotics. Colonies were then resuspended in MES (2-(N-Morpholino-)-ethanesulfonic acid) buffer (10 $\mathrm{mM} \mathrm{MgCl} 2,10 \mathrm{mM}$ MES, $150 \mu \mathrm{M}$ acetosyringone) to an optical density at $600 \mathrm{~nm}$ of 0.6 and were stored at room temperature for 2 to $3 \mathrm{~h}$. Young leaves were infiltrated by gently appressing a 1-ml syringe to the abaxial surface and depressing the plunger until a water-soaked appearance was achieved.

Histochemical detection of GUS activity in plant tissue was carried out 5 days postinfiltration, essentially as described by Dry and associates (2000). Leaves were abraded with Carborundum in $100 \mathrm{mM}$ phosphate buffer $(\mathrm{pH} \mathrm{7.0),0.1 \%} \beta$-mercaptoethanol, were vacuum filtrated with a solution containing 50 $\mathrm{mM}$ phosphate buffer ( $\mathrm{pH} 7.0), 0.1 \%$ Triton $\mathrm{X}-100$, and $1 \mathrm{mM}$ 5-bromo-4-chloro-3-indoyl glucuronide (X-gluc), and were incubated in this solution at $37^{\circ} \mathrm{C}$ overnight. The next day, tissues were fixed in 5\% formaldehyde, $5 \%$ acetic acid, and $20 \%$ ethanol for 2 to 3 hours and, finally, stored in $100 \%$ ethanol.

\section{ACKNOWLEDGMENTS}

We thank I. Dry, D. Webster, and D. Pountney for useful discussions, J. Stonor for excellent technical assistance, and W. Dawson for the gift of $30 \mathrm{~B}$ vector. This work was supported by Australian Research Council grant A09802106.

\section{LITERATURE CITED}

Ach, R. A., Durfee, T., Miller, A. B., Taranto, P., Hanley-Bowdoin, L., Zambryski, P. C., and Gruissem, W. 1997. RRB1 and $R R B 2$ encode maize retinoblastoma-related proteins that interact with a plant D-type cyclin and geminivirus replication protein. Mol. Cell. Biol. 17:50775086.

Behjatnia, S. A. A., Dry, I. B., and Rezaian, M. A. 1998. Identification of the replication-associated protein binding domain within the intergenic region of tomato leaf curl geminivirus. Nucleic Acids Res. 26:925931.

Brunetti, A., Tavazza, M., Noris, E., Tavazza, R., Caciagli, P., Ancora, G., Crespi, S., and Accotto, G. P. 1997. High expression of truncated viral 
Rep protein confers resistance to tomato yellow leaf curl virus in transgenic tomato plants. Mol. Plant-Microbe Interact. 10:571-579.

Desbiez, C., David, C., Mettouchi, A., Laufs, J., and Gronenborn, B 1995. Rep protein of tomato yellow leaf curl geminivirus has an ATPase activity required for viral DNA replication. Proc. Natl. Acad. Sci. U.S.A. 92:5640-5644.

Dry, I. B., Rigden, J. E., Krake, L. R., Mullineaux, P. M., and Rezaian, M. A. 1993. Nucleotide sequence and genome organization of tomato leaf curl geminivirus. J. Gen. Virol. 74:147-151.

Dry, I., Krake, L., Mullineaux, P. M., and Rezaian, M. A. 2000. Regulation of tomato leaf curl viral gene expression in host tissues. Mol. Plant-Microbe Interact. 13:529-537.

Frischmuth, T., and Stanley, J. 1998. Recombination between viral DNA and the transgenic coat protein gene of African cassava mosaic geminivirus. J. Gen. Virol. 79:1265-1271.

Gladfelter, H. J, Eagle, P. A., Fontes, E. P. B., Batts, L. A., and HanleyBowdoin, L. 1997. Two domains of the AL1 protein mediate geminivirus origin recognition. Virology 239:186-197.

Gleave, A. P. 1992. A versatile binary vector system with a T-DNA organisational structure conducive to efficient integration of cloned DNA into the plant genome. Plant Mol. Biol. 20:1203-1207.

Hanley-Bowdoin, L., Elmer, J. S., and Rogers, S. G. 1990. Expression of functional replication protein from tomato golden mosaic virus in transgenic tobacco plants. Proc. Natl. Acad. Sci. U.S.A. 87:14461450 .

Hanley-Bowdoin, L., Settlage, S. B., Orozco, B. M., Nagar, S., and Robertson, D. 1999. Geminiviruses: Models for plant DNA replication, transcription, and cell cycle regulation. Crit. Rev. Plant Sci. 18:71-106.

Heyraud-Nitschke, F., Schumacher, S., Laufs, J., Schafer, S., Schell, J., and Gronenborn, B. 1995. Determination of the origin cleavage and joining domain of geminivirus rep proteins. Nucleic Acids Res. 23:910-916.

Hong, Y., and Stanley, J. 1996. Virus resistance in Nicotiana benthamiana conferred by African cassava mosaic virus replication associated-protein (AC1) transgene. Mol. Plant-Microbe Interact. 4:219-225.

Hong, Y., Saunders, K., and Stanley, J. 1997. Transactivation of dianthin gene expression by African cassava mosaic virus AC2. Virology 228:383-387.

Jupin, I., Dekouchkovsky, F., Jouanneau, F., and Gronenborn, B. 1994 Movement of tomato yellow leaf curl geminivirus (TYLCV)-Involvement of the protein encoded by ORF C4. Virology 204:82-90.

Kong, L.-J., and Hanley-Bowdoin, L. 2002. A geminivirus replication protein interacts with a protein kinase and a motor protein that display different expression patterns during plant development and infection. Plant Cell 14:1817-1832.

Kong, L.-J., Orozco, B. M., Roe, J. L., Nagar, S., Ou, S., Feiler, H. S., Durfee, T., Miller, A. B., Gruissem, W., Robertson, D., and HanleyBowdoin, L. 2000. A geminivirus replication protein interacts with the retinoblastoma protein through a novel domain to determine symptoms and tissue specificity of infection in plants. EMBO (Eur. Mol. Biol. Organ.) J. 19:3485-3495.

Krake, L. R., Rezaian, M. A., and Dry, I. B. 1998. Expression of the tomato leaf curl geminivirus $C 4$ gene produces viruslike symptoms in transgenic plants. Mol. Plant-Microbe Interact. 11:413-417.

Latham, J. R., Saunders, K., Pinner, M. S., and Stanley, J. 1997. Induction of plant cell division by beet curly top virus gene C4. Plant $\mathrm{J}$. 11:1273-1283.

Laufs, J., Traut, W., Heyraud, F., Matzeit, V., Rogers, S., Schell, J., and Gronenborn, B. 1995. In vitro cleavage and joining at the viral origin of replication by the replication initiator protein of tomato yellow leaf curl virus. Proc. Natl. Acad. Sci. U.S.A. 92:3879-3883.

Lazarowitz, S. G., Pinder, A. J., Damsteegt, V. D., and Rogers, S. G. 1989. Maize streak virus genes essential for systemic spread and symptom development. EMBO (Eur. Mol. Biol. Organ.) J. 8:10231032 .

Lewandowski, D. J., and Dawson, W. O. 1998. Deletion of internal sequences results in tobacco mosaic virus defective RNAs that accumu- late to high levels without interfering with replication of the helper virus. Virology 251:427-437.

Liu, L, Saunders, K., Thomas, C. L., Davies, J. W., and Stanley, J. 1999. Bean yellow dwarf virus RepA, but not Rep, binds to maize retinoblastoma protein and the virus tolerates mutations in the consensus binding motif. Virology 256:270-279.

Nagar, S., Pedersen, T. J., Carrick, K. M., Hanley-Bowdoin, L., and Robertson, D. 1995. A geminivirus induces expression of a host DNA synthesis protein in terminally differentiated plant cells. Plant Cell 7:705-719.

Noris, E., Accotto, G. P., Tavazza, R., Brunetti, A., Crespi, S., and Tavazza, M. 1996. Resistance to tomato yellow leaf curl geminivirus in Nicotiana benthamiana plants transformed with a truncated viral C1 gene. Virology 224:130-138.

Rigden, J. E., Dry, I. B., Mullineaux, P. M., and Rezaian, M. A. 1993. Mutagenesis of the virion-sense open reading frames of tomato leaf curl geminivirus. Virology 193:1001-1005.

Rigden, J. E., Krake, L. R., Rezaian, M. A., and Dry, I. B. 1994. ORF C4 of tomato leaf curl geminivirus is a determinant of symptom severity. Virology 204:847-850.

Settlage, S. B., Miller, A. B., Gruissem, W., and Hanley-Bowdoin, L. 2001. Dual interaction of a geminivirus replication accessory factor with a viral replication protein and a plant cell cycle regulator. Virology 279:570-576.

Shivprasad, S., Pogue, G. P., Lewandowski, D. J., Hidalgo, J., Donson, J., Grill, L. K., and Dawson, W. O. 1999. Heterologous sequences greatly affect foreign gene expression in tobacco mosaic virus-based vectors Virology 255:312-323.

Sunter, G., and Bisaro, D. M. 1992. Transactivation of geminivirus AR1 and BR1 gene expression by the viral AL2 gene product occurs at the level of transcription. Plant Cell 4:1321-1331.

Sunter, G., Hartitz, M. D., Hormuzdi, S. G., Brough, C. L., and Bisaro, D. M. 1990. Genetic analysis of tomato golden mosaic virus: ORF AL2 is required for coat protein accumulation while ORF AL3 is necessary for efficient DNA replication. Virology 179:69-77.

Sunter, G., Hartitz, M. D., and Bisaro, D. M. 1993. Tomato golden mosaic virus leftward gene expression: Autoregulation of geminivirus replication protein. Virology 195:275-280.

Sunter, G., Stenger, D. C., and Bisaro, D. M. 1994. Heterologous complementation by geminivirus AL2 and AL3 genes. Virology 203:203-210.

van Regenmortel, M. H., Mayo, M. A., Fauquet, C. M., Maniloff, J. 2000. Virus nomenclature: Consensus versus chaos. Arch. Virol. 145:22272232.

van Wezel, R., Dong, X., Blake, P., Stanley, J., and Hong, Y. 2002a. Differential roles of geminivirus Rep and AC4 (C4) in the induction of necrosis in Nicotiana benthamiana. Mol. Plant Path. 3:461-471.

van Wezel, R., Dong, X., Liu, H., Tien, P., Stanley, J., and Hong, Y. 2002 b. Mutation of three cysteine residues in Tomato yellow leaf curl virus-China $\mathrm{C} 2$ protein causes dysfunction in pathogenesis and posttranscriptional gene-silencing suppression. Mol. Plant-Microbe Interact. 15:203-208

van Wezel, R., Liu, H., Tien, P., Stanley, J., and Hong, Y. 2001. Gene $C 2$ of the monopartite geminivirus Tomato yellow leaf curl virus-China encodes a pathogenicity determinant that is localized in the nucleus. Mol. Plant-Microbe Interact. 14:1125-1128.

Voinnet, O., Pinto, Y. M., and Baulcombe, D. C. 1999. Suppression of gene silencing: A general strategy used by diverse DNA and RNA viruses of plants. Proc. Natl. Acad. Sci. U.S.A. 96:14147-14152.

Wesley, S. V., Helliwell, C. A., Smith, N. A., Wang, M., Rouse, D. T., Liu, Q., Gooding, P. S., Singh, S. P., Abbott, D., Stoutjesdijk, P. A., Robinson, S. P., Gleave, A. P., Green, A. G., and Waterhouse, P. M. 2001. Construct design for efficient, effective and high-throughput gene silencing in plants. Plant J. 27:581-590.

Xie, Q., Suarez-Lopez, P., and Gutierrez, C. 1995. Identification and analysis of a retinoblastoma binding motif in the replication protein of a plant DNA virus: requirement for efficient viral DNA replication. EMBO (Eur. Mol. Biol. Organ.) J. 14:4073-4082. 